\title{
Robot Pengikut Posisi dengan Menggunakan Filter Warna HSV
}

\author{
Fitrah Triatmojo, Budi Sugandi \\ Politeknik Negeri Batam \\ Teknik Mekatronika \\ Jl. Ahmad Yanin, Batam Centre, Batam 29461, Indonesia \\ e-mail: budi_sugandi@polibatam.ac.id
}

\begin{abstract}
Abstrak
Kemajuan teknologi pengolahan citra digital banyak dimanfaatkan oleh manusia. Manfaat pengolahan citra di antaranya adalah untuk meningkatkan kualitas suatu citra, menghilangkan cacat pada citra dan mengidentifikasi objek. Dengan memanfaatkan teknologi tersebut, dapat dikembangkan suatu sistem yang dapat mendeteksi objek serta melakukan tracking. Pada penelitian ini, penulis akan membuat sebuah sistem untuk mendeteksi objek berwarna. Metode untuk mendeteksi warna penulis menggunakan filter warna HSV, metode erosi, dilasi dan thresholding. Untuk membaca jarak robot terhadap objek, digunakan metode Regresi yang nantinya akan digunakan sebagai penggerak bagi aktuator motor dc. Hasil yang dicapai dalam penelitian ini adalah sistem dapat mendeteksi objek pada jarak 50-180 cm dan mengikutinya pada jarak $60-150 \mathrm{~cm}$.
\end{abstract}

Kata kunci: Deteksi objek, Tracking objek, Filter warna HSV

\begin{abstract}
Advancement in digital processing technology have benefited to the human. One of the benefits of image processing is to improve the quality of an image, eliminate noise in and identify objects. By utilizing the technology, it can be developed a system that can detect and track objects. In this article, we develop a system to detect and track an object. We use the HSVcolor filter, erosion, dilation, and thresholding methods to detect the object. To measure the distance between object and robot, we apply the mathematical regression formula. The output of the equation is then used as actuator for the dc motor. The results achieved in this study is system can detect object in the distance range $50-180 \mathrm{~cm}$ and follow the object in the range $60-150 \mathrm{~cm}$.
\end{abstract}

Keywords: Object Detection, Object Tracking, HSV color filtering

\section{Pendahuluan}

Manusia terus melakukan inovasi-inovasi pada teknologi disaat ini. Dengan adanya kemajuan teknologi tersebut tentunya akan membuat segalanya akan menjadi lebih cepat dan mudah. Sistem otomatis tentunya menjadi pilihan tepat untuk meringankan pekerjaan manusia, dimulai dari pekerjaan mudah hingga sulit, dan ringan hingga berat. Koper atau kereta dorong tentu sudah tidak asing digunakan oleh manusia. Koper berguna untuk mengangkut barangbarang bawaan ketika hendak bepergian, lalu kereta dorong biasa digunakan untuk mengangkut barang ketika berbelanja. Sekarang ini koper dan kereta dorong tersebut banyak yang masih digerakkan langsung oleh manusia, dimana hal tersebut masih belum efisien dan tergolong merepotkan.

Nugroho, et. al [1] telah melakukan penelitian untuk membuat sistem pendeteksi gerak dan mengikuti gerakan objek. Sistem ini terhubung dengan komputer yang melaksanakan algoritma secara real time untuk mencari tahu arah gerakan dari objek. David, et.al [2] dan Rahman [3] melakukan penelitian faktor yang berpengaruh pada kinerja kamera dan pengaturan kombinasi untuk meminimalkan error fate of experiment. Hendawan, et.al [4] melakukan peneltian pengukuran jarak dengan menggunakan persamaan polinomial yang dibentuk dari perubahan nilai hue terhadap jarak.

Dalam penelitian ini, penulis mendesain robot pengikut objek dengan menggunakan kamera untuk mendeteksinya. Sistem dapat melakukan pengukuran perubahan banyak pixel terhadap jarak yang bertujuan untuk memberi batasan maksimal dan minimal pada sistem agar mengikuti objek yang telah dideteksi. Metode yang digunakan berdasarkan filter warna HSV yang dilanjutkan dengan erosi, dilasi dan thresholding. 


\section{Dasar Teori}

\subsection{Akuisisi Citra}

Akuisisi citra merupakan tahap awal untuk mendapatkan citra digital. Tujuan nya adalah untuk menentukan data yang diperlukan dan memilih metode perekaman citra digital. Tahap ini dimulai dari objek yang akan diambil gambarnya, persiapan alat-alat, dan pada pencitraannya. Dimana pencitraan adalah kegiatan transformasi dari citra tampak (foto, gambar, lukisan, dll) menjadi citra digital [2].

\subsection{Warna RGB}

Ruang warna RGB merupakan ruang warna default untuk menyimpan dan merepresentasikan gambar digital. Kita bisa mendapatkan ruang warna lain dari transformasi RGB linear atau non-linear Ruang warna RGB adalah ruang warna yang digunakan oleh komputer, kartu grafis dan monitor. Gambar 1 menunjukkan tiga komponen warna RGB (Red, Green and Blue). Warna RGB merupakan warna primer atau warna dasar dari semua warna dimana warna lain diperoleh dengan mencampur ketiga warna primer tersebut. [5]

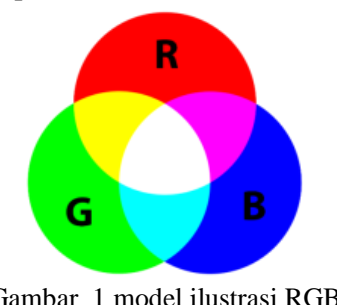

\subsection{Warna HSV (Hue, Saturation, Value)}

Warna HSV [5] diilustrasikan pada gambar 2. Hue menyatakan range warna sebenarnya, seperti merah, violet, dan kuning dan digunakan menentukan kemerahan (redness), kehijauan (greeness) [3]. Hue dideskripsikan sebagai nilai yang spesifik yang menentukan posisi warna murni sesuai pada roda warna, yang berada direntang nilai antara 0 dan 1 . Nilai 0 mengacu pada warna merah, 1/6 adalah kuning, 1/3 adalah hijau, dan sebagainya. disekitar roda warna. Saturation kadang disebut chroma, adalah kemurnian atau kekuatan warna. Warna merah yang asli nilai saturasinya adalah 1 . Warna merah yang lebih muda (lebih terang) memiliki saturasi kurang dari 1 dan warna putih memiliki nilai saturasi 0. Value adalah kecerahan dari warna. Nilainya berkisar antara 0-100 \%. Apabila nilainya 0 maka warnanya akan menjadi hitam, semakin besar nilai maka semakin cerah dan muncul variasi-variasi baru dari warna tersebut.

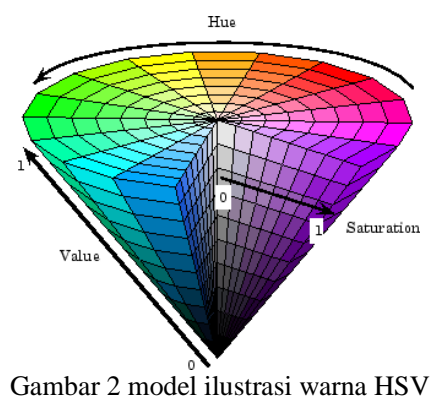

\subsection{Morfologi Filter}

Morfologi filter adalah teknik pengolahan citra yang bertujuan untuk memperbaiki citra pada gambar biner. Morfologi filter ini membutuhkan dua input berupa gambar asli dan matriks structure element [68]. Morfologi filter mempunyai dua operasi standar yaitu dilasi dan erosi. Dilasi adalah proses penggabungan titik-titik latar menjadi bagian dari objek "penumbuhan" atau "penebalan" objek citra biner. Erosi adalah proses mengecilkan atau menipiskan objek pada citra biner.

\section{Perancangan Sistem}

\subsection{Rancangan Perangkat Keras}

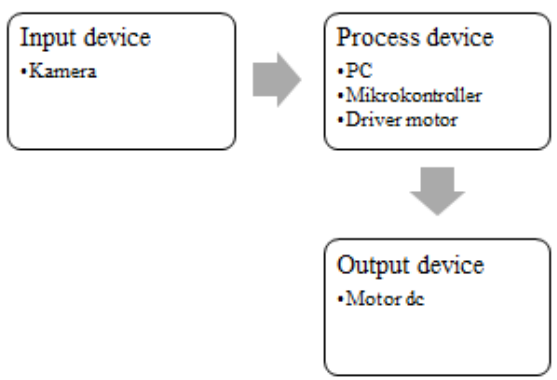

Gambar 3 Diagram Blok Perangkat keras

Diagram blok perancangan perangkat keras ditunjukkan pada gambar 3. Proses pendeteksian berawal dari kamera untuk mengambil gambar (citra). Data hasil keluaran kamera kemudian dikirim menuju controller yang berfungsi sebagai pemrosesan data. Setelah data tersebut diproses, data akan dikirimkan ke driver motor sebagai pengatur gerakan actuator pada motor.

\subsection{Rancangan Perangkat lunak}

Perancangan perangkat lunak dilukiskan pada gambar 4. Setelah citra ditangkap kamera, citra dikonversi ke citra HSV [9]. Proses selanjutnya adalah binarisasi citra menjadi citra biner untuk kemudian dilakukan proses dilasi dan erosi untuk mereduksi noise pada citra sampai didapatkan objek yang akan diikuti oleh robot. Ketika objek berhasil dideteksi maka sistem akan mengkonversi luas pixel menjadi jarak dengan 
menggunakan metode regresi polinomial. Data jarak tersebut akan diproses dan dikirimkan ke controller sebagai data serial untuk selanjutnya ditranslasikan menjadi pergerakan sistem.

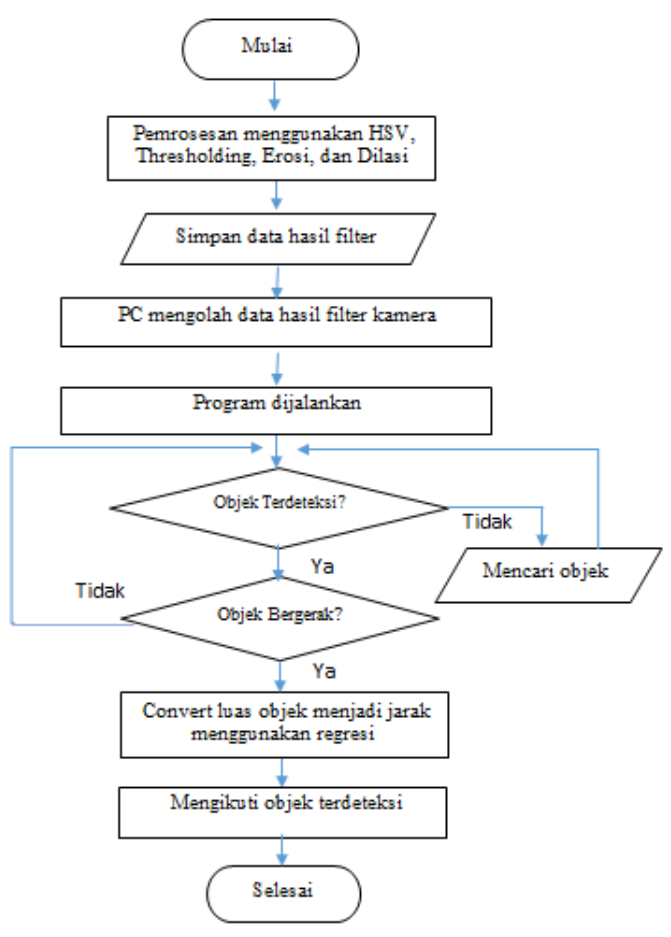

Gambar 4 Flowchart Sistem Perangkat Lunak

\section{Hasil dan Analisa}

\subsection{Pengujian Filter warna}

Pengujian ini dilakukan untuk mengatur nilai interval HSV yang akan digukanan untuk mendeteksi objek agar objek dapat dideteksi dan dipisahkan dari lingkungan atau background di sekitarnya. Gambar 5 menunjukkan hasil simulasi untuk mendeteksi warna pink. Dan didapatkan interval HSV sebagai berikut : Hue $=125-255$, Saturation $=65-255$ dan Value $=$ $175-255$.

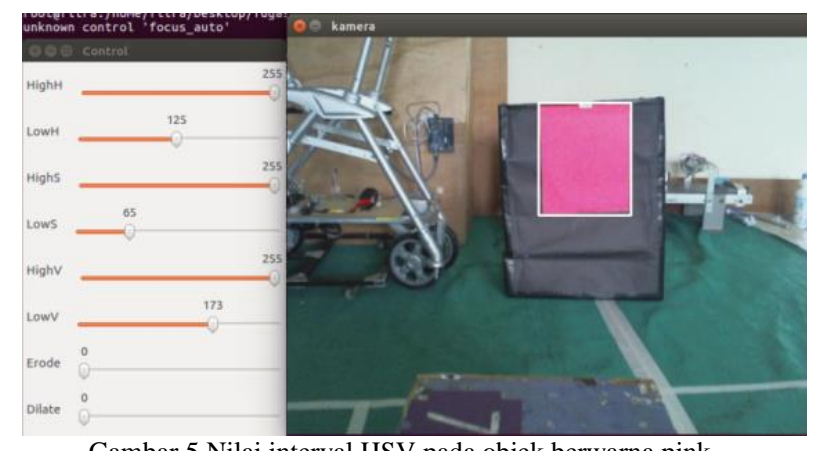

Gambar 5 Nilai interval HSV pada objek berwarna pink

\subsection{Pengujian Jarak Deteksi}

Pengujian jarak deteksi dilakukan dengan mengkoversi luas objek yang terdeteksi dengan menggunakan metode regresi polinomial. Dari pengujian ini dapat diketahui jarak mimimum dan maksimum objet dapat dideteksi. Hasil pengujian ditunjukkan pada gambar $6-8$ dengan (A) jarak $50 \mathrm{~cm}$ (B) jarak60cm, (C) jarak 70cm, (D) jarak $80 \mathrm{~cm}$, (E) jarak $120 \mathrm{~cm}$ dan (F) jarak $180 \mathrm{~cm}$. Tabel 1 menunjukkan jarak minimal dan maksimal robot dapat mendeteksi objek.

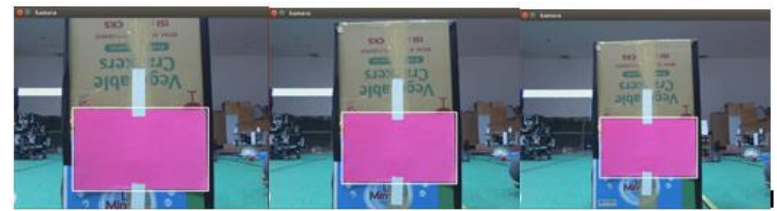

(A)

(B)

(C)

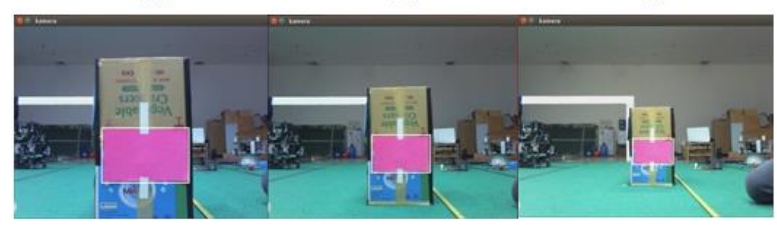

(D)

(F)

Gambar 6 Pendeteksian objek di tengah frame

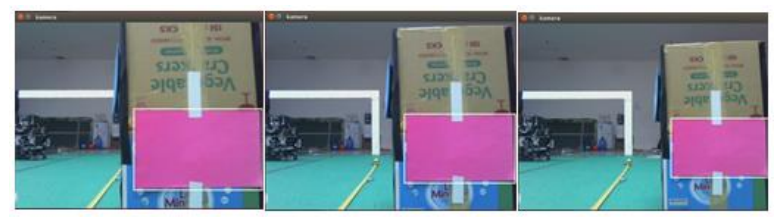

(A)

(B)

(C)

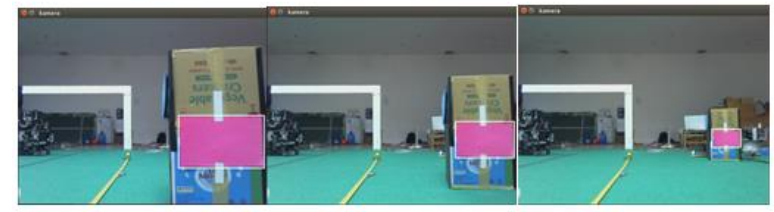

(D)

(E)

(F)

Gambar 7 Pendeteksian objek di kanan frame

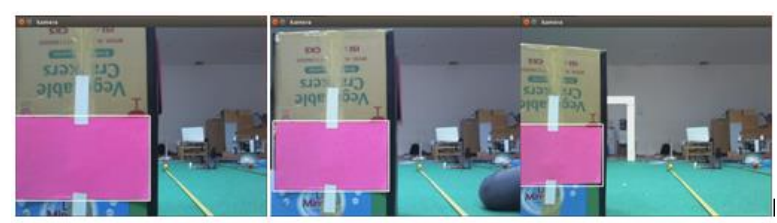

(A)

(B)

(C)

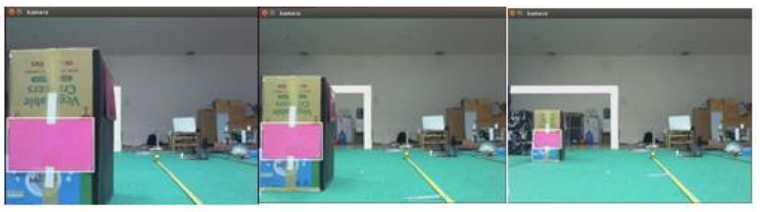

(D)

(E)

(F)

Gambar 8 Pendeteksian objek di kiri frame 
TABEL 1 DETEKSI OBJEK BERDASARKAN JARAK

\begin{tabular}{|l|l|l|l|}
\hline $\begin{array}{c}\text { Jarak } \\
(\mathrm{cm})\end{array}$ & \multicolumn{1}{|c|}{ Kiri } & \multicolumn{1}{|c|}{ Kanan } & \multicolumn{1}{|c|}{ Tengah } \\
\hline 40 & Tidak & Tidak & Tidak \\
\hline 50 & Terdeteksi & Terdeteksi & Terdeteksi \\
\hline 60 & Terdeteksi & Terdeteksi & Terdeteksi \\
\hline 70 & Terdeteksi & Terdeteksi & Terdeteksi \\
\hline 80 & Terdeteksi & Terdeteksi & Terdeteksi \\
\hline 120 & Terdeteksi & Terdeteksi & Terdeteksi \\
\hline 150 & Terdeteksi & Terdeteksi & Terdeteksi \\
\hline 190 & Tidak & Tidak & Tidak \\
\hline
\end{tabular}

\subsection{Pengujian arah putar motor ketika objek terdeteksi}

Pada bagian ini akan diuji respon gerak robot ketika kamera mendeteksi adanya objek. Pergeerakan yang akan diuji adalah gerak kea rah kanan, kiri atau depan. Dalam pengujian ini, penulis membagi frame menjadi 3 bagian yaitu bagian kiri, kanan, dan tengah. Hasil pengujian ditunjukan masing-masing oleh gambar 9-11 untuk objek yang terdeteksi sebelah kiri, kanan dan tengah dengan $\mathrm{A}$ adalah objek yang terdeteksi dan B arah gerak robot. Robot berhasil mengikuti objek yang berada di kiri, kanan dan tengah frame seperti yang ditunjukkan pada gambar 9-11.

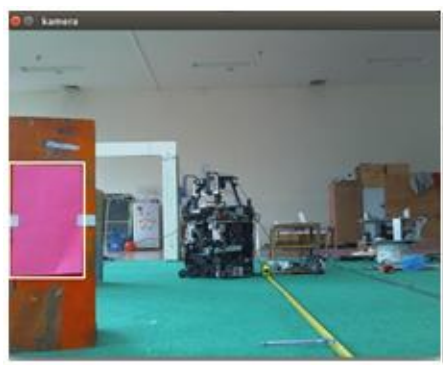

(A)

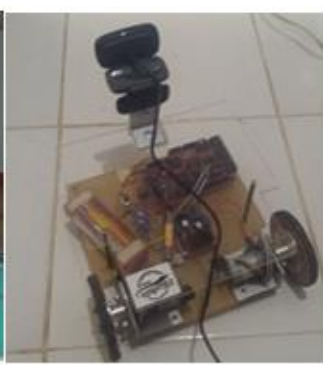

(B)
Gambar 9. Deteksi objek sebelah kiri frame

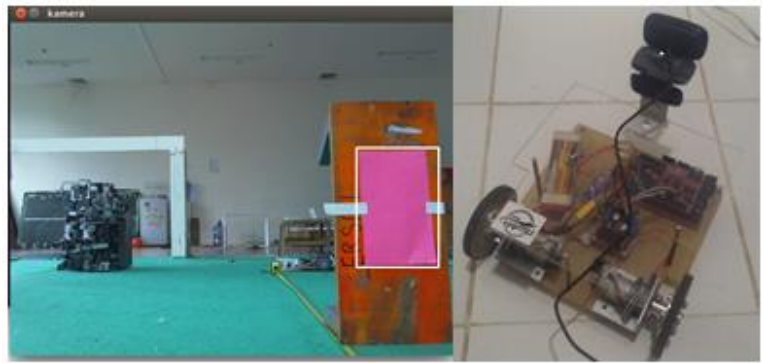

(A)

(B)

Gambar 10. Deteksi objek sebelah kanan frame

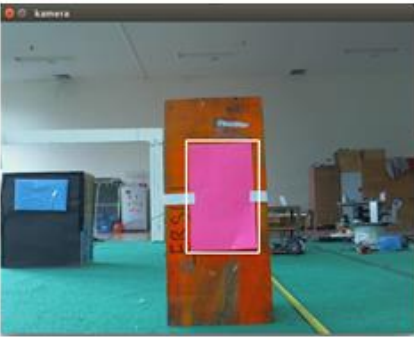

(A)

\subsection{Pengujian kemampuan robot mengikuti objek}

Pada pengujian ini akan dilakukan pengujian kemampuan robot untuk mengikuti objek. Sistem diberikan jarak minimal $50 \mathrm{~cm}$ untuk dapat mengikuti objek. Sistem akan diam jika sistem tidak mendeteksi objek pada jarak tertentu. Hasil pengujian ditunjukkan oleh tabel 2. Robot dapat mengikuti objek ketika posisi objek ada di kiri, tengah dan kanan robot pada jarak $50-180 \mathrm{~cm}$.

Tabel 2 Pengujian Kemampuan Robot Mengikuti ObJeK

\begin{tabular}{|c|c|c|c|}
\hline \multirow{2}{*}{$\begin{array}{c}\text { Jarak } \\
(\mathrm{cm})\end{array}$} & \multicolumn{3}{|c|}{ Posisi objek } \\
\cline { 2 - 4 } & kiri & Tengah & Kanan \\
\hline 40 & Gagal & Gagal & Gagal \\
\hline 50 & $\begin{array}{c}\text { Gagal dan } \\
\text { Berhasil }\end{array}$ & $\begin{array}{c}\text { Gagal dan } \\
\text { Berhasil }\end{array}$ & $\begin{array}{c}\text { Gagal dan } \\
\text { Berhasil }\end{array}$ \\
\hline 60 & Berhasil & Berhasil & Berhasil \\
\hline 70 & Berhasil & Berhasil & Berhasil \\
\hline 80 & Berhasil & Berhasil & Berhasil \\
\hline 90 & Berhasil & Berhasil & Berhasil \\
\hline 100 & Berhasil & Berhasil & Berhasil \\
\hline 110 & Berhasil & Berhasil & Berhasil \\
\hline 120 & Berhasil & Berhasil & Berhasil \\
\hline 130 & Berhasil & Berhasil & Berhasil \\
\hline 140 & Berhasil & Berhasil & Berhasil \\
\hline 150 & Berhasil & Berhasil & Berhasil \\
\hline 160 & Gagal & Gagal & Gagal \\
\hline
\end{tabular}

\section{Kesimpulan}

Pada penelitian ini telah dikembangkan suatu robot pengikut objek berdasarkan filter warna HSV. Sistem yang dibangun dapat mendeteksi objek jarak 50$180 \mathrm{~cm}$ dan dapat mengikuti objek pada jarak 60$150 \mathrm{~cm}$. Objek yang dideteksi dan diikuti ada objek berwarna ping dengan interval filter warna HSV adalah sebagai berikut : Hue $=125-255$, Saturation $=$ 65-255 dan Value $=175-255$.

Sistem ini masih mempunyai kelemahan diantaranya kurang sensitifnya robot terhadap pergerakan objek yang cepat. Hal ini salah satunya karena kurang sensitifnya kamera yang dipakai untuk mendeteksi objek. Sementara kemampuan filter warna HSV untuk mendeteksi objek berwarna sudah cukup baik. 


\section{Daftar Pustaka}

[1] H. Nugroho (2007). "Kamera Pendeteksi Gerak Menggunakan MATLAB 7.1", Universitas Guna Darma.

[2] D. Simangunsong. (2016), "Optimasi Sensor Kamera Pada Proses Identifikasi Warna Dengan Pengolahan Citra menggunakan Design of Experiment", Universitas Telkom.

[3] R. Maulana, "Pengembangan Robot Rubik dengan identifikasi warna menggunakan Sensor Kamera”, Institut Teknologi Sepuluh November.

[4] H. Soebhakti, "Pengukuran Jarak berdasarkan Ekstraksi Nilai Hue pada Citra Depth menggunakan Sensor Kinect". Politeknik Negeri Batam.

[5] S. Kolkur, (2017), "Human Skin Detection Using RGB, HSV, and YCBCr color Model", Atlantis press.

[6] H. Wolfgang. (1990). "Smoothing Techniques With Implementation in S". Springer Verlag.

[7] N Senthilkumaran. (2016), "Image Segmentation by Using Thresholding Techniques for Medical Images", India: Gandhigram Rural Institute.

[8] R. Wahyusari dan B. Haryoko. (2017) "Pemanfaatan Mathematical Morphology untuk Deteksi Tepi Batik", Jurnal Simetris, vol 8 no 1.

[9] B. Sugandi (2018), "Deteksi dan Pelacakan wajah berdasarkan warna kulit menggunakan partikel filter", Jurnal Rekayasa Elektrika, Vol 14 no 2. 